\title{
The Magnitude of Hematological Abnormalities Among COVID- 19 Patients in Addis Ababa, Ethiopia
}

This article was published in the following Dove Press journal:

Journal of Multidisciplinary Healthcare

Shambel Araya (D)
Moges Wordofa'
Mintesnot Aragaw Mamo
Yakob Gebregziabher Tsegay
Abebe Hordofa ${ }^{2,5}$
Abebe Edao Negesso
Tewodros Fasil
Betelhem Berhanu'
Hermela Begashaw
Asegdew Atlaw ${ }^{2}$
Tirhas Niguse'
Mahlet Cheru (D)
Zemenu Tamir ID
'Department of Medical Laboratory
Sciences, College of Health Sciences,
Addis Ababa University, Addis Ababa,
Ethiopia; 'Department of Medical
Laboratory, Millennium COVID-I9
Treatment and Care Centre, St. Paul
Millennium Medical College, Addis Ababa,
Ethiopia; ${ }^{3}$ Department of Medical
Biotechnology, Institute of Biotechnology,
University of Gondar, Gondar, Ethiopia;
${ }^{4}$ Research and Development Center,
College of Health Sciences, Defense
University, Addis Ababa, Ethiopia;
${ }^{5}$ Department of Medical Laboratory,
Legehare General Hospital, Addis Ababa,
Ethiopia

Shambel Araya (1) 1,2

Mintesnot Aragaw Mamo ${ }^{2,3}$

Yakob Gebregziabher Tsegay ${ }^{2-4}$

Abebe Hordofa ${ }^{2,5}$

Abebe Edao Negesso (ID)

Tewodros Fasil

Betelhem Berhanu'

Hermela Begashaw $(\mathbb{D}$

Asegdew Atlaw ${ }^{2}$

Tirhas Niguse'

Mahlet Cheru (D)

Addis Ababa University, Addis Ababa,

Ethiopia; ${ }^{2}$ Department of Medical

Millennium Medical College, Addis Ababa,

Ethiopia; ${ }^{3}$ Department of Medica

${ }^{4}$ Research and Development Center,

College of Health Sciences, Defense

University, Addis Ababa, Ethiopia;

Legehare General Hospital, Addis Ababa, Ethiopia

Correspondence: Moges Wordofa

Email heranmakmow@gmail.com
Background: Coronavirus disease 2019 (COVID-19) is a systemic infection with cardiovascular, pulmonary, gastrointestinal, neurological, and hematological manifestations. Abnormal hematological findings are thought to have a role in early risk stratification and prognostication of COVID-19 patients. However, the data on hematological abnormalities associated with the disease among Ethiopian COVID-19 patients are limited.

Objective: To determine the magnitude of hematological abnormalities among COVID-19 patients admitted at Millennium COVID-19 referral treatment center, Addis Ababa, Ethiopia. Methods: A prospective cross-sectional study was conducted among COVID-19 patients admitted to Millennium COVID-19 referral treatment center from May to July, 2020. A total of 334 COVID-19 patients were included using convenience sampling. Socio-demographic data and disease severity status of admitted patients were recorded. Three milliliters of venous blood was collected and analyzed by Beckman Coulter DXH-600 automated analyzer to determine complete blood count (CBC). The data were entered and analyzed using SPSS version 23 software. Association of age, sex, and disease severity with hematological abnormalities was analyzed using binary logistic regression. An odds ratio and $95 \%$ confidence interval were used to measure the strength of association. P-value $<0.05$ was considered as statistically significant.

Results: Of 334 admitted COVID-19 patients, the majority were males (62.3\%) and 69.8\% had moderate disease conditions. The overall magnitude of any cytopenia and pancytopenia was $41 \%$ and $1.8 \%$, respectively. The magnitude of anemia, thrombocytopenia, and leukopenia was $24.9 \%, 21.6 \%$, and $5.4 \%$, respectively. Lymphopenia $(72.2 \%)$ was the most common hematological abnormality. COVID-19 patients with severe and critical disease were more likely to develop anemia, leukocytosis, neutrophilia, and combined neutrophilialymphopenia than those with moderate disease condition, with a significant association.

Conclusion: Lymphopenia was the most common hematological abnormality observed among COVID-19 patients. Hematological abnormalities such as anemia, leukocytosis, neutrophilia, and combined neutrophilia-lymphopenia were significantly associated with disease severity. Monitoring and evaluation of hematological parameters could provide prognostic insight into the management and risk stratification of COVID-19 patients. However, further studies are required to fully understand the utility of hematological parameters for the prognosis of COVID-19 disease.

Keywords: hematological parameters, COVID-19, disease severity

\section{Introduction}

COVID-19 is caused by novel severe acute respiratory syndrome corona virus (SARS-CoV-2) which first appeared in December 2019 in Wuhan, China and quickly transformed into a global pandemic through symptomatic and asymptomatic 
person-to-person transmission mainly through respiratory droplets. ${ }^{1}$ The initial presentation of the disease ranged from mild non-specific symptoms of acute respiratory syndrome (mainly fever, cough, and myalgia) to severe acute respiratory distress and in some case leading to death. ${ }^{2-4}$ However, many aspects of the disease (transmission, infection, and treatment) are unclear and still under investigation.

The COVID-19 pandemic has heavily affected the global population. As of January, 27, 2021, there have been 100,933,425 confirmed cases and 2,169,732 deaths globally and 3,493,809 confirmed cases and 87,087 deaths in Africa. Similarly, 134,569 confirmed cases and 2075 deaths were reported from Ethiopia in December 1, $2020 .^{5,6}$

COVID-19 is a systemic infection with cardiovascular, pulmonary, gastrointestinal, neurological, and hematological manifestations. ${ }^{7,8}$ The virus also infects lymphocytes as they express angiotensin-converting enzyme 2 (ACE2) on their surface, and lymphopenia was the most prominent hematological abnormality. ${ }^{9,10}$ According to the Centers for Disease Control and Prevention guidance, leukopenia (9-25\%), leukocytosis (24-30\%), and lymphopenia (63\%) were among the most common laboratory abnormalities reported in hospitalized COVID-19 patients with pneumonia. ${ }^{11}$ Similarly, a large sample size study in China by Guan et al showed that $83.2 \%, 36.2 \%$, and $33.7 \%$ of COVID-19 patients had lymphopenia, thrombocytopenia, and leukopenia, respectively. ${ }^{12}$ These abnormalities are more eminent among severe than non-severe patients. Lymphopenia, neutrophilia, and high neutrophil-to-lymphocyte ratio are mainly associated with risk for developing acute respiratory distress syndrome (ARDS) and thus, need for ICU (intensive care unit) care. ${ }^{10,12-14}$ Similarly, other studies also indicated that lymphopenia, thrombocytopenia, leukocytosis, and neutrophilia were associated with disease progression and severity, ICU admission, and death. ${ }^{13,14}$

Early identification and timely treatment of COVID-19 patients at higher risk of developing critical disease are pivotal to prevent unfavorable clinical outcomes. ${ }^{8}$ However, nowadays, gold standard real time polymerase chain reaction (RT-PCR) test for detection of COVID-19 in nasal and throat swabs has its own limitations, especially in resource-limited settings like Ethiopia. Limited testing capacity, high false-negativity, the need for qualified personnel, high cost, and delays in obtaining results make it difficult for mass screening in a situation where the virus is rapidly spreading. ${ }^{15}$ Thus, abnormal hematological values in patients with COVID-19 may aid in earlier risk stratification and prognostication of these patients, ultimately leading to earlier interventions and ideally more favorable outcomes.

Therefore, monitoring of hematological parameters such as absolute lymphocyte and neutrophile count, platelet count, and total white blood cell (WBC) count obtained from routine and widely available $\mathrm{CBC}$ test may serve as a prognostic marker in the management and early identification of high-risk patients requiring intensive care.

\section{Methodology Study Design and Settings}

A cross-sectional study was conducted from May to July, 2020 at Millennium COVID-19 referral treatment center, Addis Ababa, Ethiopia to determine the magnitude of hematological abnormalities among admitted COVID-19 patients. The center serves as a COVID-19 referral treatment center with more than 1000 beds.

Convenience sampling technique was used to select 334 patients who tested positive for COVID-19 by RTPCR and who were admitted at the center. Patients who had been previously diagnosed with chronic disease such as kidney failure, heart and liver disease as well as those who underwent immunosuppressive therapy such as chemotherapy and/radiation for at least two months were excluded due to the fact that these conditions would affect hematological parameters.

\section{Data Collection Method and Procedures}

Socio-demographic data and disease severity status of admitted patients were collected by reviewing medical records.

Three milliliters of venous blood was collected in an EDTA vacutainer tube from each patient by experienced laboratory professionals working at the center. Beckman Coulter DXH-600 automated hematology analyzer was used to determine complete blood count (total WBC count, absolute and relative count of each WBC type, $\mathrm{RBC}$, and platelet count).

Quality of test results was maintained by running commercially prepared three level quality control (low, normal, and high) reagents before running the patient's sample. During laboratory analysis, standard operational procedures (SOP) were strictly followed; integrity of samples and reagents was regularly checked. 


\section{Operational Definitions}

According to WHO clinical management of COVID-19 interim guidance of May 27, 2020, patients were categorized into three groups to assess disease severity. ${ }^{16}$

\section{Moderate}

Symptomatic patient meeting case definition for COVID without evidence of viral pneumonia or hypoxia and/or adolescent or adult with clinical sign of pneumonia (fever, cough, dyspnea, fast breathing) but no severe pneumonia including $\mathrm{SPo}_{2} \geq 90 \%$ on room air.

\section{Severe}

Adolescent or adult with clinical sign of pneumonia (fever, cough, dyspnea, fast breathing) plus one of the following: respiratory rate $>30$ breath $/ \mathrm{min}$, severe respiratory distress; or $\mathrm{SPo}_{2}<90 \%$ on room air.

\section{Critical}

Acute respiratory distress syndrome (ARDS) within one week of known clinical insult or new or worsening respiratory symptoms, chest imaging indicating bilateral opacities not fully explained by volume overload, labor or lung collapse, respiratory failure not fully explained by cardiac failure or fluid overload, oxygenation impairment in adult and children, acute life-threatening organ dysfunction, evidence of septic shock with characteristics of persistent hypotension despite volume resuscitation in adults and children.

The cut-off value for normal and abnormal hematological parameters was determined by considering WHO criteria for defining anemia and based on immunohematological reference range for adult Ethiopians for the rest of the parameters. Accordingly, anemia was defined as hemoglobin (Hgb) value $<13 \mathrm{~g} / \mathrm{dl}$ for males aged $>15$ years and $\mathrm{Hgb}<12 \mathrm{~g} / \mathrm{dl}$ for nonpregnant women aged $>15$ years. ${ }^{17}$ In addition, leukopenia was define as total WBC count $<3.6 \times 10^{9} / \mathrm{L}$ whereas thrombocytopenia was platelet count $<150,000 / \mu \mathrm{L} .{ }^{18}$ Cytopenia was defined as the presence of either anemia or leukopenia or thrombocytopenia, whereas bi-cytopenia was characterized as the presence of two forms of cytopenia. On the other hand, pancytopenia was defined as the presence of anemia, thrombocytopenia, and leukopenia in combination. ${ }^{19}$

\section{Statistical Analysis}

The data were entered and analyzed using Statistical Package for Social Science (SPSS) version 23. Binary logistic regression model was used to determine the association between hematological abnormality and independent variables. Odds ratio (OR) and 95\% confidence interval (CI) were used to measure the strength of association. P-value $<0.05$ was considered as statistically significant.

\section{Ethical Consideration}

This study was approved by the department of Research and Ethics Review Committee (DRERC) of Addis Ababa University, College of Health Sciences, department of Medical Laboratory Science. Permission to conduct the study was obtained from Millennium COVID-19 referral treatment center. Written informed consent was obtained from each participant and confidentiality of the data was maintained throughout the study.

\section{Results}

\section{Socio-Demographic Characteristics of Study Participants}

In this study, a total of 334 admitted COVID-19 patients were included and the majority of the patients were male (62.3\%). Relatively, most of the patients (38\%) were in the age group of $\geq 56$. Regarding disease severity, $69.8 \%$ of patients had moderate disease while $12.3 \%$ were in a critical condition (Table 1).

\section{Magnitude of Hematological Abnormalities}

In the study, the overall magnitude of any cytopenia and pancytopenia was $41 \%$ and $1.8 \%$, respectively. Regarding cytopenia, anemia (24.9\%) and thrombocytopenia (21.6\%) were relatively more common. Regarding anemia severity,

Table I Characteristics of Admitted COVID-19 Patients in Millennium COVID-19 Referral Treatment Center, Addis Ababa, Ethiopia $(n=334)$

\begin{tabular}{|l|l|l|}
\hline Variable & Frequency (n) & Percentage (\%) \\
\hline Sex & & \\
Male & 203 & 62.3 \\
Female & 126 & 37.7 \\
\hline Age group (yrs.) & & \\
I8-35 & 88 & 26.3 \\
$36-55$ & 119 & 35.6 \\
$\geq 56$ & 127 & 38 \\
\hline Mean age ( \pm SD) & $49.4(17.2)$ & \\
\hline Disease Severity & \multicolumn{2}{|}{} \\
Moderate & 233 & 69.8 \\
Severe & 60 & 18 \\
Critical & 41 & 12.3 \\
\hline
\end{tabular}


Table 2 The Magnitude of Hematological Abnormalities Among COVID-19 Patients in Millennium COVID-19 Referral Treatment Center, Addis Ababa, Ethiopia $(n=334)$

\begin{tabular}{|l|l|}
\hline Hematological Abnormalities & Frequency (\%) \\
\hline Any cytopenia & $137(4 I)$ \\
Anemia & $83(24.9)$ \\
Leukopenia & $18(5.4)$ \\
Thrombocytopenia & $72(21.6)$ \\
\hline Leukocytosis & $99(29.6)$ \\
Neutrophilia & $167(50)$ \\
Lymphopenia & $241(72.2)$ \\
Lymphopenia-Neutrophilia & $29(8.7)$ \\
Pancytopenia & $6(1.8)$ \\
\hline Bi-cytopenia & \\
Leukopenia and thrombocytopenia & $16(4.8)$ \\
Leukopenia and anemia & $7(2.1)$ \\
Anemia and thrombocytopenia & $22(6.6)$ \\
\hline Anemia severity & \\
Mild & $42(12.57)$ \\
Moderate & $37(11.1)$ \\
Severe & $4(1.2)$ \\
\hline
\end{tabular}

$12.57 \%$ and $1.2 \%$ of patients had mild and severe anemia, respectively. On the other hand, $29.6 \%$ of patients had leukocytosis and half of patients had neutrophilia. The most common hematological abnormality among COVID-19 patients was lymphopenia (72.2\%) (Table 2).

The magnitude of any cytopenia was relatively higher in critical $(46.3 \%)(\mathrm{P}=0.44)$ and severe $(43.3 \%)(\mathrm{P}=0.6)$ than in moderate (39.5\%) COVID-19 patients. On the other hand, the magnitude of pancytopenia was similar in moderate $(2.1 \%)$ and critical $(2.5 \%)(\mathrm{P}=0.85)$ patients (Table 3).

The magnitude of anemia was relatively higher among males (26.4\%) and in the age group of 18-35 years (28.4\%). On the other hand, the odds of developing anemia was 2.35 times higher in patients with severe than moderate disease condition with a significant association $(\mathrm{P}=0.007)$. Patients in critical disease conditions were two times more likely to develop anemia than moderate patients but with a marginal association $(\mathrm{P}=0.06)$ (Table 4).

The magnitude of lymphopenia was highest in the age group of $\geq 56$ years (78.7\%) with no statistical significance $(\mathrm{P}=0.25)$. The magnitude was also almost similar among critical $(75.6 \%)$, severe $(65.0 \%)$, and moderate $(73.4 \%)$ COVID-19 patients with no significant association with disease severity (Table 5).

The findings of this study showed that thrombocytopenia was more frequent among females $(24.6 \%)(\mathrm{P}=0.28)$ and younger (18-35years) (23.9\%) COVID-19 patients. However, thrombocytopenia did not show a significant difference among gender and age groups $(\mathrm{P}>0.05)$. In contrary to previous reports, this study also showed more thrombocytopenic cases among moderate COVID-19 cases than severe and critical cases despite a lack of statistically significance difference among these groups $(\mathrm{P}>0.05)$ (Table 6).

The overall magnitude of leukopenia among COVID19 patients was low (5.4\%) (Table 2). The current finding also showed that only $7.3 \%$ of moderate and $2.4 \%$ of critical patients had leukopenia, with no statistical association $(\mathrm{P}=0.39)$ (Table 7).

Table 3 The Association of Any Cytopenia and Pancytopenia with Disease Severity, Age, and Sex Among COVID-I9 Patients in Millennium COVID-19 Referral Treatment Center, Addis Ababa, Ethiopia $(n=334)$

\begin{tabular}{|c|c|c|c|c|c|c|c|c|}
\hline \multirow[t]{2}{*}{ Variables } & \multicolumn{4}{|c|}{ Any Cytopenia } & \multicolumn{4}{|c|}{ Pancytopenia } \\
\hline & No, n (\%) & Yes, n (\%) & OR (95 Cl) & P-value & No, n (\%) & Yes, n (\%) & OR (95\% Cl) & P-value \\
\hline \multicolumn{9}{|l|}{ Age group (yrs.) } \\
\hline $18-35$ & 45 (5I.I) & $43(48.9)$ & I & & $86(97.7)$ & $2(2.3)$ & I & \\
\hline $36-55$ & $81(68.1)$ & 38 (31.9) & $0.49(0.28-0.86)$ & 0.014 & 117 (98.3) & $2(1.7)$ & $0.8(0.1-5.6)$ & 0.78 \\
\hline$\geq 56$ & 7I (55.9) & $56(44.1)$ & $0.8 I(0.46-I .4 I)$ & 0.45 & $125(98.4)$ & $2(1.6)$ & $0.65(0.1-5.0)$ & 0.57 \\
\hline \multicolumn{9}{|l|}{ Sex } \\
\hline Female & 74 (58.7) & $52(41.3)$ & I.0 (0.63-I.58) & 0.99 & $123(97.6)$ & $3(2.4)$ & I.6 (0.32-8.5) & 0.56 \\
\hline Male & $123(59.1)$ & 85 (40.9) & 1 & & $205(98.6)$ & $3(1.4)$ & 1 & \\
\hline \multicolumn{9}{|l|}{ Severity } \\
\hline Moderate & $|4|(60.5)$ & $92(39.5)$ & I & & 228 (97.9) & $5(2.1)$ & I & \\
\hline Severe & $34(56.7)$ & $26(43.3)$ & I.I7 (0.65-2.09) & 0.6 & $60(100)$ & 0 & 0 & 0.997 \\
\hline Critical & $22(53.7)$ & $19(46.3)$ & $1.3(0.66-2.59)$ & 0.44 & $40(97.6)$ & I (2.4) & $1.2(0.1-I I)$ & 0.85 \\
\hline
\end{tabular}


Table 4 The Association of Anemia with Disease Severity, Age, and Sex Among COVID-19 Patients in Millennium COVID-19 Referral Treatment Center, Addis Ababa, Ethiopia $(n=334)$

\begin{tabular}{|c|c|c|c|c|}
\hline \multirow[t]{2}{*}{ Variables } & \multicolumn{4}{|l|}{ Anemia } \\
\hline & No, n (\%) & Yes, n (\%) & OR $(95 \% \mathrm{CI})$ & P-value \\
\hline \multicolumn{5}{|c|}{ Age-groups (yrs.) } \\
\hline $18-35$ & $63(71.6)$ & $25(28.4)$ & I & \\
\hline $36-55$ & $96(80.7)$ & $23(19.3)$ & $0.59(0.3 \mathrm{I}-\mathrm{I} .15)$ & 0.12 \\
\hline$\geq 56$ & 92 (72.4) & $35(27.6)$ & $0.92(0.49-1.74)$ & 0.80 \\
\hline \multicolumn{5}{|l|}{ Sex } \\
\hline Female & $98(77.8)$ & $28(22.2)$ & $0.77(0.45-\mid .3 I)$ & 0.34 \\
\hline Male & I53 (73.6) & $55(26.4)$ & 1 & \\
\hline \multicolumn{5}{|l|}{ Severity } \\
\hline Moderate & I86 (79.8) & $47(20.2)$ & I & \\
\hline Severe & $38(63.3)$ & $22(36.7)$ & $2.35(1.26-4.37)$ & 0.007 \\
\hline Critical & 27 (65.9) & $14(34.1)$ & $2.0(0.96-4.19)$ & 0.063 \\
\hline
\end{tabular}

Table 5 The Association of Lymphopenia with Disease Severity, Age, and Sex Among COVID-19 Patients in Millennium COVID-19 Referral Treatment Center, Addis Ababa, Ethiopia $(n=334)$

\begin{tabular}{|c|c|c|c|c|}
\hline \multirow[t]{2}{*}{ Variables } & \multicolumn{4}{|c|}{ Lymphopenia } \\
\hline & No, n (\%) & Yes, n (\%) & OR $(95 \% \mathrm{CI})$ & P-value \\
\hline \multicolumn{5}{|c|}{ Age-groups (yrs.) } \\
\hline 18-35 & $26(29.5)$ & $62(70.5)$ & & \\
\hline $36-55$ & $40(33.6)$ & $79(66.4)$ & $0.8(0.44-1.5)$ & 0.47 \\
\hline$\geq 56$ & $27(21.3)$ & 100 (78.7) & I.5 (0.77-2.76) & 0.25 \\
\hline \multicolumn{5}{|l|}{ Sex } \\
\hline Female & $42(33.3)$ & $84(66.7)$ & $0.7(0.4 I-I . I)$ & 0.11 \\
\hline Male & $5 I(24.5)$ & $157(75.5)$ & I & \\
\hline \multicolumn{5}{|l|}{ Severity } \\
\hline Moderate & $62(26.6)$ & I7I (73.4) & I & \\
\hline Severe & $21(35.0)$ & $39(65.0)$ & $0.7(0.38-1.3)$ & 0.26 \\
\hline Critical & $10(24.2)$ & 31 (75.6) & $1.0(0.46-2.2)$ & 0.98 \\
\hline
\end{tabular}

Table 6 The Association of Thrombocytopenia with Disease Severity, Age, and Sex Among COVID-19 Patients in Millennium COVID19 Referral Treatment Center, Addis Ababa, Ethiopia. $(n=334)$

\begin{tabular}{|c|c|c|c|c|}
\hline \multirow[t]{2}{*}{ Variables } & \multicolumn{4}{|c|}{ Thrombocytopenia } \\
\hline & No, n (\%) & Yes, n (\%) & OR (95\% Cl) & P-value \\
\hline \multicolumn{5}{|l|}{ Age groups (yrs.) } \\
\hline $18-35$ & $67(76.1)$ & $21(23.9)$ & 1 & \\
\hline $36-55$ & $96(80.7)$ & $23(19.3)$ & $0.76(0.4-1.5)$ & 0.43 \\
\hline$\geq 56$ & $99(78)$ & $28(22)$ & $0.87(0.45-1.7)$ & 0.68 \\
\hline \multicolumn{5}{|l|}{ Sex } \\
\hline Female & $95(75.4)$ & $31(24.6)$ & I.3 (0.79-2.3) & 0.28 \\
\hline Male & $167(80.3)$ & $4 I(19.7)$ & I & \\
\hline \multicolumn{5}{|l|}{ Severity } \\
\hline Moderate & $182(76.8)$ & $55(23.2)$ & 1 & \\
\hline Severe and critical & $88(83.8)$ & $17(16.2)$ & $0.64(0.35-1.16)$ & 0.144 \\
\hline
\end{tabular}


Table 7 The Association of Leukopenia with Disease Severity, Age, and Sex Among COVID-19 Patients in Millennium COVID-19 Referral Treatment Center, Addis Ababa, Ethiopia $(n=334)$

\begin{tabular}{|c|c|c|c|c|}
\hline \multirow[t]{2}{*}{ Variables } & \multicolumn{4}{|c|}{ Leukopenia } \\
\hline & No, n (\%) & Yes, n (\%) & OR (95\% CI) & P-value \\
\hline \multicolumn{5}{|c|}{ Age groups (yrs.) } \\
\hline $18-35$ & 79 (89.8) & $9(10.2)$ & 1 & \\
\hline $36-55$ & $113(95)$ & $6(5)$ & $0.5(0.16-1.47)$ & 0.2 \\
\hline$\geq 56$ & $124(97.6)$ & $3(2.4)$ & $0.23(0.06-0.89)$ & 0.03 \\
\hline \multicolumn{5}{|l|}{ Sex } \\
\hline Female & II 6 (92.1) & $10(7.2)$ & $2(0.72-5.2)$ & 0.19 \\
\hline Male & $200(96.2)$ & $8(3.8)$ & 1 & \\
\hline \multicolumn{5}{|l|}{ Severity } \\
\hline Moderate & $216(92.7)$ & $17(7.3)$ & I & \\
\hline Severe & $60(100)$ & 0 & 0 & 0.99 \\
\hline Critical & $40(97.6)$ & I (2.4) & $0.4(0.05-3.24)$ & 0.39 \\
\hline
\end{tabular}

Table 8 Association of Combined Lymphopenia-Neutrophilia with Disease Severity, Age, and Sex Among COVID-19 Patients in Millennium COVID-19 Referral Treatment Center, Addis Ababa, Ethiopia $(n=334)$

\begin{tabular}{|c|c|c|c|c|}
\hline \multirow[t]{2}{*}{ Variables } & \multicolumn{4}{|c|}{ Lymphopenia-Neutrophilia } \\
\hline & No, n (\%) & Yes, n (\%) & OR $(95 \% \mathrm{Cl})$ & P-value \\
\hline \multicolumn{5}{|c|}{ Age-groups (yrs.) } \\
\hline $18-35$ & $80(90.9)$ & $8(9.1)$ & I & \\
\hline $36-55$ & $108(90.8)$ & II (9.2) & $1.03(0.39-2.76)$ & 0.94 \\
\hline$\geq 56$ & $117(92.1)$ & $10(7.9)$ & $0.82(0.3-2.3)$ & 0.71 \\
\hline \multicolumn{5}{|l|}{ Sex } \\
\hline Female & $116(92.1)$ & $10(7.9)$ & $0.8(0.36-1.8)$ & 0.61 \\
\hline Male & $189(90.9)$ & $19(9.1)$ & 1 & \\
\hline \multicolumn{5}{|l|}{ Severity } \\
\hline Moderate & $221(94.8)$ & $12(5.2)$ & I & \\
\hline Severe & $49(81.7)$ & II (18.3) & $4.1(1.7-9.9)$ & 0.002 \\
\hline Critical & $35(85.4)$ & $6(14.6)$ & $3.3(1.1-9.7)$ & 0.027 \\
\hline
\end{tabular}

In the binary logistic regression analysis of combined lymphopenia-neutrophilia with disease severity, COVID19 patients with severe and critical disease had 4.1- and 3.3-times increased odds of having combined lymphopenia-neutrophilia, respectively, than moderate patients with a significant association $(\mathrm{P}<0.005)$ (Table 8$)$.

In another regression analysis of leukocytosis with age-group and disease severity, patients in the agegroup of $\geq 56$ years had 2.3 times increased odds of developing leukocytosis with a significant association $(\mathrm{P}=0.011)$. On the other hand, patients with severe and critical health conditions had 2.6 and 2.4 times, respectively, increased risk of developing leukocytosis $(\mathrm{P}<0.05)$ (Table 9).
The study from current finding also showed that individuals in the age group of $\geq 56$ years had a 2.5 times increased risk of developing neutrophilia $(\mathrm{P}=0.002)$. The result also indicated that females were less likely to develop neutrophilia ( $\mathrm{P}=0.007)$. In addition, the study revealed that patients with severe and critical disease had a 2.7- and 3.3-times increased risk of having neutrophilia, respectively $(\mathrm{P}<0.005)$ (Table 10$)$.

\section{Discussion}

This study aimed to determine the magnitude of hematological abnormalities among COVID-19 patients. Despite increasing efforts to control or reduce the transmission of the virus, it is transmitting at an alarming rate. Provided 
Table 9 Association of Leukocytosis with Disease Severity, Age, and Sex Among COVID-19 Patients in Millennium COVID-I9 Treatment Center, Addis Ababa, Ethiopia $(n=334)$

\begin{tabular}{|c|c|c|c|c|}
\hline \multirow[t]{2}{*}{ Variables } & \multicolumn{4}{|c|}{ Leukocytosis } \\
\hline & No, n (\%) & Yes, n (\%) & OR $(95 \% \mathrm{CI})$ & P-value \\
\hline \multicolumn{5}{|c|}{ Age-groups (yrs.) } \\
\hline $18-35$ & 69 (78.4) & $19(21.6)$ & 1 & \\
\hline $36-55$ & $89(74.8)$ & $30(25.2)$ & $1.2(0.6-2.4)$ & 0.5 \\
\hline$\geq 56$ & $77(60.6)$ & $50(39.4)$ & $2.3(1.2-4.4)$ & 0.011 \\
\hline \multicolumn{5}{|l|}{ Sex } \\
\hline Female & $93(73.8)$ & $33(26.2)$ & $0.77(0.5-1.3)$ & 0.31 \\
\hline Male & $142(68.3)$ & $66(31.7)$ & I & \\
\hline \multicolumn{5}{|l|}{ Severity } \\
\hline Moderate & 178 (76.4) & $55(23.6)$ & 1 & \\
\hline Severe & $35(58.3)$ & $25(41.7)$ & $2.6(1.4-4.8)$ & 0.002 \\
\hline Critical & $22(53.7)$ & $19(46.3)$ & $2.4(1.2-4.8)$ & 0.015 \\
\hline
\end{tabular}

Table 10 Association of Neutrophilia with Disease Severity, Age, and Sex Among COVID-19 Patients in Millennium COVID-19 Referral Treatment Center, Addis Ababa, Ethiopia

\begin{tabular}{|c|c|c|c|c|}
\hline \multirow[t]{2}{*}{ Variables } & \multicolumn{4}{|c|}{ Neutrophilia } \\
\hline & No, n (\%) & Yes, n (\%) & OR $(95 \% \mathrm{CI})$ & P-value \\
\hline \multicolumn{5}{|c|}{ Age-groups (yrs.) } \\
\hline 18-35 & $55(62.5)$ & $23(37.5)$ & I & \\
\hline $36-55$ & $63(52.9)$ & $56(47.1)$ & I.5 (0.82-2.6) & 0.2 \\
\hline$\geq 56$ & 49 (38.6) & $78(6 \mid .4)$ & $2.5(1.4-4.5)$ & 0.002 \\
\hline \multicolumn{5}{|l|}{ Sex } \\
\hline Female & $75(59.5)$ & $51(40.5)$ & $0.5(0.3-0.84)$ & 0.007 \\
\hline Male & $92(44.2)$ & 116 (55.8) & I & \\
\hline \multicolumn{5}{|l|}{ Severity } \\
\hline Moderate & $134(57.5)$ & $99(42.5)$ & 1 & \\
\hline Severe & $22(36.7)$ & $38(63.3)$ & $2.7(1.5-4.9)$ & 0.001 \\
\hline Critical & II (26.8) & 30 (73.2) & $3.3(1.5-7.0)$ & 0.02 \\
\hline
\end{tabular}

that the virus has high infectivity, early diagnosis and management of the disease is vital. Along with molecular tests such as RT-PCR, investigation of the change in hematological parameters obtained from easily accessible and inexpensive routine $\mathrm{CBC}$ is essential for early diagnosis and risk stratification of patients.

In this study, the overall magnitude of any cytopenia and pancytopenia among COVID-19 patients was $41 \%$ and $18 \%$, respectively. At admission, the majority of patients had lymphopenia (72.2\%), whereas 50\% had neutrophilia, $29.6 \%$ presented with leukocytosis, while $24.9 \%$ and $21.6 \%$ of patients had anemia and thrombocytopenia, respectively. On the other hand, only $5.4 \%$ of patients had leukopenia. The Center for Disease Control in the United States and Huang et al in Wuhan, China identified lymphopenia as the most common hematological abnormality among COVID-19 patients, with lower magnitude compared to the current study $(63 \%) .^{11,20}$ Similarly, a relatively lower magnitude of lymphopenia (42\%) was reported among younger COVID-19 patients with mild to moderate disease condition. $^{21}$ On the other hand, a relatively higher magnitude of lymphopenia was observed among hospitalized COVID-19 patients in Singapore, $83 \%^{22}$ and in China, $83.2 \%{ }^{12}$ However, other studies from China reported $70.3 \%^{23}$ and $72.3 \%{ }^{24}$ of lymphopenia which is similar to our study. Age and clinical condition of patients could be determinant factors for the magnitude of 
lymphopenia and its progression among COVID-19 patients. $^{25}$

Several studies identified lymphopenia as a reliable marker of disease progression and severity with magnitude higher in dead and/or ICU patients than non-severe or "survivor" patients. ${ }^{12,20,22,23,25}$ Other studies by Fan et al ${ }^{22}$ in Singapore, and Arentz et $\mathrm{al}^{26}$ in the USA, Washington among critically ill patients also revealed the positive correlation of ${ }^{27}$ lymphopenia with disease fatality. It has also been indicated as an important prognostic tool among COVID-19 patients. ${ }^{8}$

$\mathrm{Li}$ et $\mathrm{al}^{27}$ compared hematological parameters on admission between alive and dead COVID-19 patients. Their finding indicated lower median lymphocyte and higher median neutrophile count among non-survivors than "survivor" patients. However, these parameters were not associated with an increased risk of death. In line with this, the higher magnitude of lymphopenia in our study was not considered as predictor of disease severity. This might be due to a comparable magnitude of lymphopenia among moderate $(73.4 \%)$, severe $(65 \%)$, and critical (75.6\%) COVID-19 patients.

Yang et al also indicated an insignificant difference in lymphopenia between non-severe and severe patients. ${ }^{28}$ Provided that lymphopenia is not specific for COVID-19 and also acommon finding in the elderly, the predictive capacity of lymphopenia will be improved if it is combined with other parameters such as neutrophilia and high neutrophil-to-lymphocyte ratio. ${ }^{13}$ In this regard, our study demonstrated that severe and critical COVID-19 patients had 4.1- and 3.3-fold increased odds of developing combined neutrophilia-lymphopenia respectively, than moderate patients, with a significant association $(\mathrm{P}<0.05)$.

In most studies, neutrophilia was a common finding in severe patients. A study in Singapore among 138 hospitalized patients showed that neutrophilia was significantly higher in patients requiring admission to ICU $\left(11.6 \times 10^{9} / \mathrm{L}\right.$ vs $\left.3.5 \times 10^{9} / \mathrm{L}\right){ }^{22}$ Similarly, our study also showed that neutrophilia was more prominent in severe $(\mathrm{OR}=2.7$, 95\% $\mathrm{CI}=1.5-4.9, \mathrm{P}=0.001)$ and critical $(\mathrm{OR}=3.3,95 \%$ $\mathrm{CI}=1.5-7.0, \mathrm{P}=0.02)$ than moderate patients. Similar to our study, Qin et $\mathrm{al}^{29}$ and Gong et $\mathrm{al}^{30}$ reported significantly higher neutrophil count in severe than non-severe patients $(\mathrm{P}<0.001)$, and it was also shown among nonsurvivors compared to survivors in a study by $\mathrm{Li}$ et al. ${ }^{27}$ Another study by Zhang et al among 82 dead COVID-19 patients also revealed that $74.3 \%$ of them had neutrophilia on admission and this increased to $100 \%$ in 24 hours before death. ${ }^{31}$ The presence of neutrophilia could be related to cytokine storm that characterizes COVID-19 disease. However, careful interpretation is required as neutrophilia could be due to bacterial co-infections and treatment used for the disease.

The overall magnitude of anemia in our study was $24.9 \%$, which is similar to a retrospective study by Bellmann-Weiler et al of $24.7 \%,{ }^{32}$ while it was lower compared to Tao et al, ${ }^{33}$ who reported $35.5 \%$. This study also reported that severe patients had a significantly associated increased risk of developing anemia $(\mathrm{OR}=2.35,95 \%$ $\mathrm{CI}=1.26-4.37, \mathrm{P}=0.007)$ than moderate patients, while critical patients had 2 times increased risk of developing anemia with a marginal association $(\mathrm{P}=0.063)$. Similarly, Bellmann-Weiler et al also revealed a significant association between anemia and increased risk of in-hospital mortality $(\mathrm{OR}=3.73,95 \% \mathrm{CI}=1.74-78)$. Tao et al also indicated an increased risk of developing severe disease condition in anemic than non-anemic group. In contrast to our finding, Cai et $\mathrm{al}^{34}$ observed no significant association between hemoglobin levels and disease severity. However, careful interpretation is required as low hemoglobin could be attributed to underlying comorbidities, age, and other factors.

With regard to leukocytosis, both severe $(\mathrm{OR}=2.6$, 95\% $\mathrm{CI}=1.4-4.8, \mathrm{P}=0.002)$ and critical $(\mathrm{OR}=2.4,95 \%$ $\mathrm{CI}=1.2-4.8, \mathrm{P}=0.015)$ patients were significantly associated with leukocytosis. Similarly, a multicenter retrospective study in China revealed that leukocytosis on admission of COVID-19 patients was associated with increased risk of death in hospital. ${ }^{35}$ Zhou et $\mathrm{al}^{36}$ also showed that non-survivors were significantly associated with having leukocytosis compared to survivors $(\mathrm{P}<0.001)$.

Even though there is a difference among studies in predictive capacities of hematological parameters for COVID-19 patients, the need to consider these parameters for early identification of high-risk patients requiring intensive care is rapidly growing.

With regard to the correlation of hematological abnormalities with age and sex, the overall magnitude of hematological abnormalities such as anemia, thrombocytopenia, lymphopenia, and combined neutrophilialymphopenia was comparable among the age groups as well as between males and females. However, COVID-19 patients in the age group of $\geq 56$ years had 2.3- and 2.5-times increased odds of having leukocytosis $(\mathrm{P}=0.011)$ and neutrophilia $(\mathrm{P}=0.002)$, respectively. 
Similarly, a study by Liang et $\mathrm{al}^{37}$ reported a significantly higher neutrophil count among $\geq 50$ years old COVID-19 patients than among younger ( $<50$ years) ones. However, contrary to our finding, the total lymphocyte and platelet count was significantly lower in older ( $\geq 50$ years) than younger patients. On the other hand, according to the present finding, COVID-19 female patients had significantly lower odds of having neutrophilia than male patients. It has been indicated that the total leukocyte and neutrophil count increase progressively in males until the age of 55 years. $^{38}$

As a limitation, coagulation profiles such as D-dimer were not assessed. Besides, acomparative study between survivors and non-survivors would be more reliable to demonstrate the impact of COVID-19 on hematological parameters.

\section{Conclusion}

Lymphopenia is the most common hematological abnormality observed in COVID-19 patients. Hematological abnormalities such as anemia, combined neutrophilia-lymphopenia, leukocytosis, and neutrophilia are significantly associated with disease severity. Monitoring and evaluation of hematological parameters could provide prognostic insight into management and risk stratification of COVID-19 patients. However, further studies are required to realize the role of hematological parameters for the prognosis of COVID-19 disease.

\section{Data Sharing Statement}

The data-sets used or analyzed during the current study are available from the corresponding author on reasonable request.

\section{Ethical Clearance}

Ethical clearance was obtained from Addis Ababa University, College of Health Science, Department of Medical Laboratory Science ethical review committee and it was in accordance with the principles of the Helsinki II declaration.

\section{Consent for Publication}

Not applicable.

\section{Acknowledgment}

We would like to thank study participants (patients) for their willingness to take part in the study and all data collectors for their active participation. We are also grateful to Millennium COVID-19 referral treatment center, Addis Ababa for the permission to conduct the study.

\section{Funding}

There is no funding to report.

\section{Disclosure}

The authors declared that they have no conflicts of interest for this work.

\section{References}

1. Firas A, Rabi MSAZ, Kasasbeh GA, Salameh DM, Amjad DA-N. SARS-CoV-2 and coronavirus disease 2019: what we know so far. Pathogens. 9(3):231.

2. Zu ZY, Jiang MD, Xu PP, et al. Coronavirus disease 2019 (COVID-19): a perspective from China. Radiology. 2020;200490.

3. Guo Y-R, Cao Q-D, Hong Z-S, et al. The origin, transmission and clinical therapies on coronavirus disease 2019 (COVID-19) outbreak-an update on the status. Mil Med Res. 2020;7(1):1-10.

4. Adhikari SP, Meng S, Wu Y-J, et al. Epidemiology, causes, clinical manifestation and diagnosis, prevention and control of coronavirus disease (COVID-19) during the early outbreak period: a scoping review Infectious Diseases of Poverty. 2020;9(1):1-12.

5. WHO. Novel Corona virus (2019-nCov) situation report 2020. Available from: https://www.who.int/timorleste/emergencies/novelcoronavirus-2019/novel-coronavirus-(2019-ncov)-situation-reports. Accessed February 24, 2021.

6. Worldometer CV Reported cases and deaths by country, territory and conveyance. Available from: https://www.worldometers.info/corona virus/?utm_campaign=homeAdvegas $1 ? \% 20$. Accessed February 24, 2021.

7. Gavriatopoulou M, Korompoki E, Fotiou D, et al. Organ-specific manifestations of COVID-19 infection. Clinical and Experimental Medicine. 2020;20(4):493-506.

8. Ins ET, Elalamy I, Kastritis E, et al. Hematological findings and complications of COVID-19. Am J Hematol. 2020;95:834-847. doi:10.1002/ajh.25829

9. Xu H, Zhong L, Deng J, et al. High expression of ACE2 receptor of 2019-nCoV on the epithelial cells of oral mucosa. Int J Oral Sci. 2020;12.

10. Terpos E, Ntanasis-Stathopoulos I, Elalamy I, et al. Hematological findings and complications of COVID-19. Am J Hematol. 2020;95(7):834-847.

11. Prevention CfDCa. Interim clinical guidance for management of patients with confirmed Coronavirus Disease (COVID-19) 2020. Available from: gov/coronavirus/2019-ncov/hcp/clinical-guidancemanagement-patients.html.https://www.cdc. Accessed February 24, 2021.

12. Guan W, Ni Z, Hu Y, et al. Clinical characteristics of coronavirus disease 2019 in China. $N$ Engl $J$ Med. 2020;382:1708-1720. doi:10.1056/NEJMoa2002032

13. Agbuduwe C, Basu S. Haematological manifestations of COVID-19: from cytopenia to coagulopathy. Eur J Haematol. 2020;105(5): 540-546. doi:10.1111/ejh.13491

14. Liao D, Zhou F, Luo L, et al. Haematological characteristics and risk factors in the classification and prognosis evaluation of COVID-19. a retrospective cohort study. Lancet Haematol. 2020;7(9):e671-e8. doi:10.1016/S2352-3026(20)30217-9

15. Antonio Russo CM, Starace M, Astorri R, Calò F, Coppola N. Current status of laboratory diagnosis for COVID-19: A narrative review. Infect Drug Resist. 2020;13:2657-2665. doi:10.2147/IDR. S264020 
16. WHO. Clinical management of COVID-19: interim guidance, 27 May 2020. World Health Organization. 2020 Available from: https://apps.who.int/iris/handle/10665/332196.

17. WHO. Haemoglobin concentrations for the diagnosis of anemia and assessment of severity: VMNIS Vitamin and Mineral Nutrition Information System. Report of a WHO scientific group. 2011 Available from: http://www.who.int/vmnis/indica tors/haemoglobin/en.

18. Tsegaye A,Messele T, Tilahun T, Hailu E, et al. Immunohematological reference ranges for adult ethiopians. Clin Diagnostic Lab Immunol. 1999;6:410-414. doi:10.1128/CDLI.6.3.410-414.1999

19. Lewis SM, Bain BJ, Bates I, Dacie JV. Approach to Diagnosis and Classification of Blood Diseases. 10th ed. Philadelphia, PA, USA: Churchill Livingstone; 2006.

20. Huang CW, Y, Li X, Ren L, et al. Clinical features of patients infected with 2019 Novel Coronavirus in Wuhan, China. Lancet. 2020;395:497-506. doi:10.1016/S0140-6736(20) 30183-5

21. Xu XW, Wu XX, Jiang XG, et al. Clinical findings in a group of patients infected with the 2019 Novel Coronavirus (SARS-Cov-2) Outside of Wuhan, China: retrospective case series. BMJ. 2020;368: m606. doi:10.1136/bmj.m606

22. Fan BE Ching VCL, Chan SSW, et al. Hematologic parameters in patients with COVID-19 infection. Am J Hematol. 2020;95:131-134.

23. Wang $\mathrm{DH}, \mathrm{Hu} \mathrm{B}, \mathrm{Hu} \mathrm{C}$, et al. Clinical characteristics of 138 hospitalized patients with 2019 Novel Coronavirus-Infected Pneumonia in Wuhan. China Jama. 2020;323:1061-1069. doi:10.1001/jama.2020. 1585

24. Liu KF, Fang YY, Deng Y, et al. Clinical Characteristics of Novel Coronavirus Cases in Tertiary Hospitals in Hubei Province. Chin Med J. 2020;133:1025-1031.

25. Artur Słomka MK, Zekanowska E. Coronavirus disease 2019 (COVID-19): A short review on hematological manifestations. Pathogens. 2020;9:6.

26. Arentz M, Yim E, Klaff L, et al. Characteristics and outcomes of 21 critically ill patients with COVID-19 in Washington State. JAMA. 2020;323:1612-1614. doi:10.1001/jama.2020.4326

27. Li Q, Cao Y, Chen L, et al. Hematological features of persons with COVID-19. Leukemia. 2020;34(8):2163-2172. doi:10.1038/s41375020-0910-1
28. Yang X, Yue Y, Xu J, et al. Clinical course and outcomes of critically ill patients with SARS-CoV-2 pneumonia in Wuhan, China: a single-centered, retrospective, observational study. Lancet Respir Med. 2020;;8(5):475-481.

29. Qin $\mathrm{C}$, Zhou L, Hu Z, et al. Dysregulation of immune response in patients with COVID-19 in Wuhan, China. Clin Infect Dis. 2020;71 (15):762-768.

30. Gong J, Ou J, Qiu X, et al. A tool to early predict severe 2019-novel coronavirus pneumonia (COVID-19): a multicenter study using the risk nomogram in Wuhan and Guangdong, China. Clinical Infectious Diseases. 2020;71(15):833-840.

31. Zhang B, Zhou X, Qiu Y, et al. Clinical characteristics of 82 death cases with COVID-19. PLOS ONE. 2020;15(7):e0235458. doi: 10.1371/journal.pone.0235458

32. Bellmann-Weiler R, Lanser L, Barket R, et al. Prevalence and predictive value of anemia and dysregulated iron homeostasis in patients with COVID-19 infection. J Clin Med. 2020;9(8):2429.

33. Tao $\mathrm{Z}$, Jing $\mathrm{Xu}$, Chen $\mathrm{W}$, et al. Anemia is associated with severe illness in COVID-19: A retrospective cohort study. $J$ Med Virol;2021;93:1478-1488. doi: 10.1002/jmv.26444

34. Cai SH, Liao W, Chen SW, Liu LL, Liu SY, Zheng ZD. Association between obesity and clinical prognosis in patients infected with SARS-CoV-2. Infect Dis Poverty. 2020;9:80. doi:10.1186/s40249-02000703-5

35. Xu, PP, Tian RH, Luo S, Zu ZY, et al. Risk factors for adverse clinical outcomes with COVID-19 in China: a multicenter, retrospective, observational study. Theranostics. 2020;10:6372-6383. doi: $10.7150 /$ thno.46833

36. Zhou P, Yang XL, Wang XG, et al. A pneumonia outbreak associated with a new coronavirus of probable bat origin. Nature. 2020;579:270-273. doi:10.1038/s41586-020-2012-7

37. Liang J, Nong S, Jiang L, et al. Correlations of disease severity and age with hematology parameter variations in patients with COVID-19 pre- and post-treatment. J Clin Lab Anal. 2021;35:e23609.

38. Bain B, England JMJ. Normal haematological values: sex difference in neutrophil count. $\mathrm{Br}$ Med. 1975;1:306-309. doi:10.1136/ bmj.1.5953.306
Journal of Multidisciplinary Healthcare

\section{Publish your work in this journal}

The Journal of Multidisciplinary Healthcare is an international, peerreviewed open-access journal that aims to represent and publish research in healthcare areas delivered by practitioners of different disciplines. This includes studies and reviews conducted by multidisciplinary teams as well as research which evaluates the results or conduct of such teams or healthcare processes in general. The journal

\section{Dovepress}

covers a very wide range of areas and welcomes submissions from practitioners at all levels, from all over the world. The manuscript management system is completely online and includes a very quick and fair peer-review system. Visit http://www.dovepress.com/testimonials. php to read real quotes from published authors. 